УДК 316.75:794:004.946

\title{
ВИДЕОИГРЫ В КОНТЕКСТЕ ПОСТНЕКЛАССИЧЕСКОЙ КУЛЬТУРЫ
}

\author{
Галанина Екатерина Владимировна1,2, \\ galanina@tpu.ru \\ Шаев Юрий Михайлович 3 , \\ existentia20065@yandex.ru
}

\author{
${ }^{1}$ Национальный исследовательский Томский политехнический университет, \\ Россия, 634050, г. Томск, пр. Ленина, 30. \\ 2 Томский государственный университет, \\ Россия, 634050, г. Томск, пр. Ленина, 36. \\ 3 Пятигорский государственный университет, \\ Россия, 357532, г. Пятигорск, пр. Калинина, 9.
}

Галанина Екатерина Владимировна, кандидат философских наук, доцент Школы инженерного предпринимательства, Национальный исследовательский Томский политехнический университет; доцент кафедры культурологии, теории и истории культуры Института искусств и культуры Томский государственный университет.

Шаев Юрий Михайлович, кандидат философских наук, доцент кафедры исторических и социально-философских дисциплин, востоковедения и теологии Пятигорского государственного университета.

Статья посвящена исследованию видеоигр в контексте постнеклассической культуры. С одной стороны, видеоигры являются порождением современной культуры, находящейся на постнеклассическом этапе своего развития, связанном с новым типом рациональности и философским дискурсом постмодерна. С другой стороны, видеоигры как новые медиа, обладающие мифотворческой силой и вовлекающие субъекта в свое пространство, приводят в действие архачческие семантические пласты. Видеоцгры оказывают значительное влияние на массовое сознание, формируя идейные и ценностно-смысловые установки, и могут быть исследованы как продукт мифотворчества и мифодизайна. Цель статьи - исследовать видеоигры как неомифологический феномен в контексте постнеклассической культуры. Методы: общефилософские методы исследования, сравнительно-исторический метод, герменевтический анализ, методы прикладной людологии. Результаты. Выделены и описаны основные черты постнеклассической культуры. Видеоигры исследованы как продукт постнеклассической культуры, отражающий основные ее характеристики и опыт мироощущения современного человека. Сделан вывод о том, что постнеклассическая культура, легитимизируя различные типы рациональности и дискурса, приводя кобразу нестабильного, хаотичного и неравновесного мира, актуализируя вытесненные прежде классической культурой архаические представления, оказывается близка мифу в своем мировоззрении. Видеоигры как неомифологический феномен демонстрируют следующие черты постнеклассики: эклектичность, использование техники бриколажа, символизм, сотворчество и нелинейность.

Ключевые слова: Видеоигра, постнеклассическая культура, игра, постмодерн, миф, бриколаж, эклектика, символизм, нарратив, нелинейность, сотворчество. 


\section{Введение}

Авторы предлагают исследовать видеоигры как феномен постнеклассической культуры, в котором отражаются основные ее специфические черты, особенности мироощущения современного человека, его опыт познания действительности и ценностносмысловой пласт эпохи пост. Для постнеклассической культуры характерны эклектика и смысловая многослойность, симуляция и размывание границ реального и виртуального, сетевой принцип организации знания, плюрализм истин и учет социокультурного контекста при формировании любого типа знания. Видеоигры выступают продуктом постнеклассической культуры, в них мы вполне можем обнаружить отражение основных ее черт.

Схема «классика-неклассика-постнеклассика» была сформулирована в эпистемологии и философии науки В.С. Степиным для описания различных типов научной рациональности. Он выделяет три типа рациональности и четыре научные революции, которые приводят к трансформации оснований естественно-научной картины мира. Так, научная революция XVII в. привела к становлению классического естествознания, далее радикальные изменения в устоявшейся картине мира конца XVIII - начала XIX вв. привели к формированию нового неклассического естествознания, и в конце XX в. рождается постнеклассическая наука, примером которой выступает синергетика [1].

Если классический тип рациональности ориентировался на объективность научного знания и поиск абсолютной истины, выявление устоявшихся закономерностей и утверждал исключительную роль человеческого разума в процессе познания мира, то неклассический тип рациональности актуализирует вопрос плюральности истин и проблему иррационального в человеке. Постнеклассика фокусирует внимание на ситуативности, интерсубъективности и процессуальности научного знания [2].

Постнеклассическая рациональность включает субъекта в процесс познания, отмечает социокультурную обусловленность научного знания и имеет дело со сложными самоорганизующимися системами. Уходят в прошлое устоявшиеся модели классической науки, в центре внимания постнеклассической науки находятся открытые системы, характеризующиеся состоянием нестабильности, неопределенности и неравновесности. Нелинейность и случайность становятся атрибутивными характеристиками бытия. Формируется постнеклассический образ мира как динамического единства хаоса и космоса. Объекты этого мира характеризуются сложностью, изменчивостью, нелинейностью, уровневой организацией, взаимодействием элементов и обратной связью, способностью к самоорганизации и саморазвитию. Таким образом, как отмечает Н.З. Алиева, постнеклассика «формирует плюрализм как мировоззренческий принцип, обосновывающий необходимость толерантности, терпимости во всех сферах человеческой культуры и бытия» [3].

Подобное различение вполне применимо и к историческим типам философствования [4], к развитию социального знания [5] и к этапам развития культуры в целом. Сам термин «постнеклассика», как утверждает С.В. Гавриленко, репрезентативен как в отношении науки и эпистемологии, так и культурологии, философии, искусства [6]. А.Я. Флиер предлагает трехчастную модель «классика-неклассика-постнеклассика» использовать как модель развития культуры, поскольку существует взаимосвязь этапов становления культуры с этапами эволюции знания [7]. М.А. Можейко отмечает, что неклассика может быть соотнесена с модернистским проектом в философии, а постнеклассика - с постмодернизмом [4].

Постнеклассика взамен утверждения универсальной рациональности логоцентричной классической культуры предлагает современной культуре легитимацию абсолютно 
всех видов рациональности и типов дискурса. Для постнеклассической культуры характерна установка на нелинейность, эклектичность, изменчивость, становление, открытость, процессуальность, плюральность и т. д. В культуре пост легитимизированы все типы рациональности, в ней сочетаются различные пласты, соотносимые как с классическими формами, так и предполагающие постмодернистские опыты с формой и содержанием, творчески сочетающие поверхностность и глубину. Постнеклассическая культура достаточно сложна и многослойна, ее феномены содержат множество смысловых пластов и интерпретационных перспектив.

В качестве примера можно привести современное искусство, которое предполагает различные смысловые прочтения и дает возможность как глубинной интерпретации, соотносимой с элитарными интеллектуальными кругами, так и одновременно отсылают нас к житейскому опыту и расхожим идеям информационного пространства рядового потребителя массовой культуры.

Цель статьи - исследовать видеоигры как неомифологический феномен в контексте постнеклассической культуры. В ряде работ наш исследовательский коллектив уже проанализировал и выявил мифологическое содержание видеоигр: это и присутствие архаической мифологической семантики, образов, архетипов, мифологем и т. д., а также конструирование неомифологических виртуальных миров, образов героического и новых мифов [8-13]. В рамках данной работы мы сосредоточим свое внимание на исследовании специфики видеоигр как феномена постнеклассической культуры и формы современного мифотворчества.

\section{Эклектика и бриколаж}

Постнеклассика ставит под вопрос основополагающие для классической культуры установки на универсальность истин и законов бытия, взрывает традиционные оппозиции возможного и действительного, проводит последовательную деструкцию субъектобъектной оппозиции и каждой ее составляющей. Это приводит к фрагментарному миру постнеклассической культуры с его эклектикой, ризоматичностью, полисемантизмом, многослойностью и возможностью сочетания несочетаемого по принципу «все дозволено».

Современная визуальная культура и современное искусство достаточно ярко демонстрируют нам эти особенности. Неомифологизм как творческое заимствование и переработка образов классической культуры и мифологии, их эклектическое сочетание и переплавка в новые художественные формы становится одной из значимых характеристик современной культуры [14]. Как отмечает О.В. Строева, современная визуальная культура, используя коллаж и эклектику, конструирует неомиф, который отсылает нас к мифам, сказкам и другим жанрам литературы и театра [15].

Эклектика здесь сочетается с архаическим приемом бриколажа. К. Леви-Строс описал бриколаж как свойственный мифологическому мышлению своеобразный логический способ установления смысловых взаимосвязей между явлениями, способствующий разрешению фундаментальных противоречий. Бриколер создает новое смысловое и образное единство на основе уже имеющейся совокупности средств и инструментов, проводя ее своеобразную инвентаризацию [16]. В подобной «логике отскока», используя подручные средства и умножая один уровень значения другим или даже несколькими, создавались архаические мифы. К. Леви-Строс пишет, что миф имеет многослойную структуру, за которой мы можем усмотреть некую матрицу значений, однако при любом прочтении каждый его план отсылает нас к иному плану, каждый миф - к другому мифу [17]. Действие подобной бриколажной логики исследователи обнаруживают и в современном 
искусстве, где художественный бриколаж позволяет выстраивать «поле размытых значений вокруг общего смыслового ядра» [18, с. 154] и находит отражение в коллажах, ассамбляжах, инсталляциях, реди-мейдах и т. д.

Современные видеоигры (в первую очередь в жанрах фэнтези и приключения) также в своем содержании проводят своеобразную игру с мифологическим архаическим содержанием. Подобным примером многослойности и бриколажа могут послужить игры серии The Elder Scrolls, где в визуальном плане соседствуют образцы архитектуры, отсылающие к готическому, романскому стилям и греческой классике, а в сюжете и игровом нарративе присутствуют идеи повторяемости исторического процесса, идеи соединения прошлого и настоящего в акте возврата. Здесь также можно найти отсылки к христианству, переосмысление августиновских проективных метафор, в которых история подобна летящей стреле, вместе со стоическими и ницшеанскими идеями круговорота. В диалогах и монологах героев, при внимательном их анализе, можно найти соединение идей стоической философии и неокантианства и даже некоторых современных конструктивистских взглядов. В целом многие игры жанра $R P G$ эклектично соединяют образные, ценностно-смысловые и культурно-исторические пласты различных эпох воедино, создавая из «подручных средств» бриколера собственное виртуальное целое, пространство нового мифа, в котором происходит действие игры. Как правило, в чистом виде здесь не присутствует мифология определенного народа, она подвергается творческому переосмыслению и изменению и лишь отсылает нас к известным мифологическим образам и сюжетам.

Кроме использования архетипических элементов видеоигры также продуцируют акротипические образы массовой культуры, трансформируя традиционные мифологические образы и вплетая их в мозаичную картину мира современного человека. Акротипические образы соотнесены с современным видением героя и героического в условиях массовой культуры. Таковы, например, образы супергероя, солдата чести, крутого мачо, роковой красотки. Примерами игр, эксплуатирующих подобные шаблонные образы, являются серии игр Resident Evil, Far Cry [10].

Таким образом, в отличие от мифа архаического, миф в современности, как отмечает С.В. Тихонова, редко имеет систематизированный характер [19]. Вместо гармоничных мифологических систем прошлого применительно к современности мы можем говорить о существовании разнообразных и разрозненных мифов, которые являются отголоском архаики и вместе с тем - продуктом современного мифотворчества и мифодизайна.

\section{Символизм}

Многие видеоигры предполагают символизм, который может осуществляться на различных уровнях - смысловом, нарративном, образно-визуальном, интертекстуальном и пр. Помимо символизма, напрямую отсылающего к мифологическим представлениям, некоторые игры содержат в себе психоаналитические идеи. В целом психоанализ часто использует мифологические сюжеты для трактовки своих идей, о чем писал П. Рикер [20].

В видеоиграх психоаналитические идеи активно используются в структуре нарратива и образах персонажей. В качестве примера возьмем игру Silent Hill 2 (2001). Главный герой - Джеймс Сандерленд - приезжает в мрачный город Сайлент Хилл, получив письмо, в котором говорится о возможной встрече с его женой по имени Мэри. Однако, как выясняется, его супруга умерла три года назад и не вполне ясно, кто является автором письма. После приезда в город с героем начинают происходить странные события. Он 
встречает девушку по имени Мария, которая внешне очень похожа на его умершую жену, однако она работает стриптизершей в местном клубе. Далее на улицах города начинают появляться различные монстры, с которыми главный герой начинает сражаться. И постепенно становится ясно, что сам город выбрал Джеймса, для того чтобы заставить страдать (ведь именно он убил свою тяжело болевшую жену три года назад, не в силах видеть ее мучения, и после этого потерял память).

В городе Джеймс встречает людей, которые также совершили преступления под влиянием обстоятельств, и город заставляет их испытывать страдания. Здесь мы встречаем Анжелу - девушку, убившую своего отца, который насиловал ее. Джеймс спасает ее от монстра (Abstract Daddy), похожего на два тела, обтянутые плотью, движения которых напоминают половой акт. Здесь очевидны классические психоаналитические сюжеты, отсылающие к детской психологической травме. Джеймс встречает Эдди Домбровски парня, страдающего от избыточного веса и считающего, что над ним смеются и издеваются окружающие. Эдди встречает Джеймса с пистолетом в руках и в окружении мертвых тел, пытаясь заверить, что это не он их убивал. Становится очевидным, что монстры являются проекцией страхов, негативных эмоций и неосознаваемых желаний. Так, например, Джеймс встречает таких монстров, как манекен (Mannequin), представляющий собой существ, составленных из двух пар женских ног; медсестру (Zombie Nurse), которая воплощает женский образ в форме медсестры с окровавленными бинтами, обмотанными вокруг головы, скрывающими лицо. Данные монстры отражают подавленные эротические желания Джеймса, жена которого долгое время болела, и одновременно отсылают к смыслам, связанным с локусами болезни и больницы.

Интересно отметить, что в основном монстры представляют собой существ, составленных из частей тела человека. Мы могли бы сказать, что здесь проявляются психоаналитические образы, отсылающие к идеям Ж. Делеза и Ф. Гваттари о «теле без органов» [21]. Сложно сказать, задумывались или нет разработчики о таких идейных параллелях, однако сама видеоигра вполне адекватно отражает постнеклассические установки и переосмысление психоаналитических сюжетов: проекций своей внутренней топологии желаний и страхов на топосы пространства, идеи травматичности реальности как таковой.

\section{Сотворчество}

Постнеклассическая рациональность включает субъекта, ценностно-целевые структуры его деятельности и сам социокультурный контекст в процесс познания. И. Пригожин и И. Стенгерс замечают: «Что бы мы ни называли реальностью, она открывается нам только в процессе активного построения, в котором мы участвуем» [22, с. 364]. При всем утверждении постмодерном смерти субъекта, нивелирования всякого рода субъективности и растворения ее в дискурсивных практиках «бытие субъекта в культуре продолжается, и бытие это характеризуется не только потреблением, но и творением» [23, с. 111]. П.Д Тищенко также пишет о том, что происходит переход «от анонимного всеобщего субъекта классического рационализма, через погруженную в контекстуальные особенности и инструментальные обстоятельства познавательной деятельности субъективность (множественной и в себе, и в отношении к другим) к субъектности уникальной личности, которая дает меру и единство миру в ответственном поступке выборе себя и другого (иного, чужого, близкого и далекого во времени и пространстве)» [24].

Постнеклассический текст приобретает черты конструктора, детали которого выстраиваются в произвольном порядке согласно воли читателя. С.Н. Оводова пишет, что «такой подход соответствует поливариантности и многоуровневости». Сам текст по 
существу становится некой «совокупностью возможных вариантов своего существования» [23, с. 111]. Взаимодействие с постнеклассическим текстом осуществляется как интерактивность, требующая от читателя определенных действий, а не только восприятия и понимания, как это было в классике. Если классика не предоставляла наблюдателю практически никакой знаковой альтернативы в герменевтическом плане, то постнеклассика несет в себе «посыл синергетического хаоса» и полисемантизма [25].

Идеи сотворчества автора и концепт открытого произведения, «которое определяется «полем» различных интерпретационных возможностей» [26, с. 171], перенос нарративного центра на читателя, сочетание доступных для обывательской интерпретации эпизодов и наличие более глубоких смыслов, актуализация которых требует достаточно высокой степени эрудиции и интеллектуальной культуры, в полной мере проявляются в современных видеоиграх, что позволяет рассматривать их как продукт именно постнеклассической культуры.

Традиционно произведения кино и литературы не предполагают такой интерактивности и активного вмешательства субъекта. Здесь участие читателя ограничивается попытками домыслить ключевые идеи, вынести оценочные суждения, актуализировать те или иные интерпретационные перспективы. Видеоигры же представляют собой новый медиум, который создает такой тип повествования, в котором ключевое место занимает интерактивность и свобода действий субъекта.

Э. Аарсет понимает видеоигры как текст в широком смысле, как кибертекст, форму эргодической литературы. В работе «Кибертекст: перспективы эргодической литературы» он вводит термин «эргодическая литература», который требует от читателя нетривиальных усилий для своего прочтения [27]. Если в классических романах от читателя требуется лишь скользить глазами по страницам книги в правильном порядке, то сюжет эргодической литературы читателю необходимо выстраивать самостоятельно.

Многие видеоигры обладают чертами эргодической литературы, поскольку в них, чтобы получить доступ к развитию сюжета, надо также прилагать различного рода усилия, совершать физические действия, которые напрямую влияют на развитие игры. Каждый пользователь получает разный результат, который зависит от его выбора. Кибертекст представляет собой текст, на который пользователь оказывает непосредственное воздействие, при этом оставаясь потребителем текста.

Э. Аарсет пишет о том, что если интерпретация письменного текста происходит в голове у субъекта, то пользователь кибертекста управляет текстом непосредственно. Он производит не просто герменевтическое толкование текста, но, по сути, создает новый текст, физически, воздействуя и трансформируя текстовые структуры. Таким образом, смыслы, заложенные в произведениях литературы и кино, эмоции, которые испытывает субъект от их восприятия, его варианты интерпретаций по большому счету определены автором, в том время как в видеоиграх игрок конструирует собственные смыслы и опыт в процессе игры.

В некоторых видеоиграх смыслы и сюжет игроку необходимо достраивать самому. Так, например, в серии игр Dark Souls сюжет во многом игроку приходится выстраивать самостоятельно, ориентируясь на небольшие кванты информации, подаваемые через диалоги персонажей по ходу игрового процесса. Разработчики даже выпустили специальную энциклопедию, в которой представлена информация о сюжете и персонажах само по себе явление интересное - своего рода нарратив о нарративе. В чем-то это напоминает литературные эксперименты У. Эко, написавшего интеллектуальный роман «Имя розы» [28], а затем выпустивший «Заметки на полях “Имени розы”» [29], представляющие собой своего рода справочник-путеводитель по роману, в котором разъясняются 
сложные пассажи и различные отсылки к историческим и философским сюжетам, которые для неискушенного читателя не вполне очевидны.

Сам по себе выбор, возможность которого предлагают многие видеоигры, часто не предполагает наличие определенного «правильного» варианта. В играх мы сталкиваемся с относительностью категорий добра и зла. Это также можно соотнести с установками постнеклассической культуры, связанными с моральным релятивизмом. Более того, данный релятивизм оказывается наполнен своего рода «экзистенциальной конкретикой», необходимостью действия, предполагающего развитие динамики игры, а не отвлеченные оценочные рассуждения без необходимости совершения конкретных поступков.

Видеоигры как новые медиа включают субъекта в процесс создания смыслов и познания действительности. В них аудитория становится непосредственным участником, активно использующим инструментальные возможности современных информационнокоммуникационных технологий. В результате пользовательских манипуляций изменяются сама структура и форма организации информации, образов, объектов и текста. Креативность самих игроков таким образом встраивается в структуру игрового процесса.

К. Кремин исследует видеоигры как форму искусства, которая создается разработчиками и игроками, «оживляющими» игру [30]. Он отмечает, что мы не просто играем в видеоигры, но создаем их в этом процессе. Опираясь на работы Ж. Делеза и Ф. Гваттари, К. Кремин рассматривает видеоигры как художественную форму, для которой само действие становится неотъемлемой частью эстетики и которая характеризуется иммерсивностью и взаимодействием своих различных элементов (игроков, аватаров, игровых объектов). Он пишет о том, что игрок, держа в руках контроллер, становится частью «машинного ассамбляжа», расширяясь таким образом до происходящего на экране. Мы расширяем границы своей телесности посредством видеоигр, вкладывая в них свои силы, умения, действия, чувства и эмоции и т. д. И это главное, что отличает видеоигры от других художественных форм, - эстетическая составляющая видеоигр реализуется только в процессе игры и при участии игроков [30].

М. Маклюэн также отмечал, что электронные медиа, являясь продолжением нервной системы современного человека, делают его активным участником процесса коммуникации. Так, например, зритель осуществляет постоянный творческий диалог с изображением на экране. Электронные медиа возвращают человека в племенное состояние, в котором царствует миф. Опираясь на М. Маклюэна, мы можем говорить о том, что сегодня новое племенное сообщество электронной культуры, соединенное в одну сеть, делает субъекта не просто активным потребителем, но и сотворцом, что достаточно ярко демонстрируют видеоигры. Сила современного мифотворчества, согласно М. Маклюэну, заключается в отказе электронных медиа как мифических форм от потребителя в пользу производителя. «Зритель или читатель сейчас должен быть сотворцом» [31, с. 345]. Таким образом, мы можем рассматривать видеоигры как феномен постнеклассической культуры, включающий аудиторию в креативный процесс, что является новым мифологическим измерением. 


\section{Нелинейность}

Нелинейность как ключевая характеристика постнеклассического типа рациональности оказывается созвучной современным информационно-коммуникационным технологиям и глобальному обществу. Постнеклассика имеет дело со сложными, нестабильными самоорганизующимися системами, традиционные методы исследования к которым более не применимы. Поэтому постнеклассическая наука актуализирует некогда вытесненные классической культурой архаические представления о конструктивной роли хаоса, концепт которого теперь переосмысляется, он перестает восприниматься как отсутствие всякой упорядоченности. Новая постнеклассическая картина мира может быть описана в терминах неустойчивости, неопределенности, случайности, динамики, когерентности, становления и т. д. Необратимость, неравновесность, нелинейность создают в новом нестабильном мире порядок из хаоса.

Однако И. Пригожин и И. Стенгерс отмечают неоднозначность самих понятий порядка и хаоса. «У нас нет даже способа говорить о переходе от порядка к хаосу!» [22, с. 319]. В этой связи философия постмодерна использует термин «хаосмос», обозначающий такое состояние среды, которое невозможно однозначно отнести ни к категории хаоса, ни к категории космоса и которое характеризуется «бесконечным потенциалом упорядочения (смыслопорождения) при отсутствии наличного порядка (семантики) [32]. Хаосмос содержит в себе потенциал всех возможных форм и смыслов вне каких-либо иерархий, за пределами рациональности и дискурсивности.

Здесь нам следует отметить обращение к архаической семантике понятия «хаос» как безграничной потенции всего сущего, присущей мифологическому сознанию. Ж. Делез и Ф. Гваттари понимают хаос как «виртуальную совокупность потенциальностей, которая становится наблюдаемой в последующей актуализации» [33, с. 130].

Понятие «хаосмос» раскрывается Ж. Делезом и Ф. Гваттари в описании концептов: «тело без органов», «ризома». Образ ризомы стал одним из символов постмодернистского мировоззрения [34]. Ризома представляет собой корневище без единого центра и структуры. Образ ризомы может обозначать нелинейность и множественность интерпретационных моделей, объяснительных схем и движений мысли. В качестве примера мы можем привести роман «Поминки по Финнегану» Дж. Джойса, построенный как «система, обладающая множественным потенциалом развития, ведь каждый читатель склонен найти свою собственную трактовку этого универсума» [35, с. 37].

Нелинейность выступает чертой, сближающей видеоигры и постнеклассические научные, а также философские представления. В современных видеоиграх данные идеи реализуются в нелинейности нарратива и геймплея. Конечно, мы можем найти видеоигры и без нарратива вовсе, и с жестко заданной сюжетной линией, на изменение которой практически невозможно повлиять. Тем не менее часто в видеоиграх, особенно в жанре $R P G$, присутствует разветвление сюжетной линии, множество альтернативных сценариев и квестов, которые можно выполнять практически в любом порядке и в любое время. Игры с открытым миром (Grand Theft Auto III, 2001) и в режиме песочницы (серия игр Minecraft), в которых игрок может свободно действовать, следуя или отключая игровые цели или выстраивая их самостоятельно, наиболее полно воплощают принцип нелинейности.

Рассмотрим в качестве примера реализации постнеклассических представлений видеоигру с элементами интерактивного кино Detroit: Become Human (2015), которая затрагивает этические вопросы существования андроидов - человекоподобных роботов, наделенных высокоразвитым искусственным интеллектом, начинающих осознавать себя и бороться за свои права. В данной игре возможно более десяти концовок. Игрок 
последовательно играет за трех различных андроидов: Коннора, Кэру и Маркуса, и по сути игра объединяет три сюжетные линии в едином пространстве. Проходя сюжет, связанный с Коннором, игрок управляет андроидом, ведущим расследование по делу о нападении андроидов-девиантов на людей. Играя за Кэру, игрок попадает в ряд сложных ситуаций, требующих решения - поступить «справедливым» образом (если уместно говорить о справедливости как категории, которую научились осознавать андроиды вместе с другими составляющими человеческой этики) или действовать в рамках системы предписанных алгоритмов. Играя за Маркуса, игрок, как и в случае с Кэрой, сталкивается с непростым этическим выбором несколько раз, что в итоге влияет на «расстановку сил» и конечный результат игры. В завершении игры сюжетные линии трех персонажей пересекаются. Многое зависит от действий игрока, который управлял персонажами. Концовка игры (могут быть варианты с гибелью всех или некоторых персонажей, восстанием андроидов и т. д.) представляет собой некую результирующую, которая соотнесена с действиями игрока в своеобразных «точках бифуркации»-ключевых моментах выбора линии поведения. Здесь мы вполне видим проявление постнеклассических идей, связанных со стохастичностью и неустойчивостью системы (потенциальных направлений развития игрового нарратива), синергетических закономерностей, идей сотворчества реципиента-игрока, который сам создает нарратив и его же прочитывает.

Осмысливая Detroit: Become Human, возможно дать различные оценки игровых событий, которые весьма неоднозначны. Например, идея о появлении у андроидов сознания и тесно связанные с ней социальные проблемы, идея возможности или невозможности признания субъектности андроида, идея «цифрового колониализма» - желание видеть в технике и окружающей человека технической реальности только объект и ресурс и неумение видеть Иное, Другого. Стоит отметить, что внимание к объектам действительности в их «вещном» своеобразии и относительной автономности в плане использования в системах смыслов характерно для постнеклассического культуры последних десятилетий. Так, например, в работах Б. Латура разворачивается критика инструментального подхода к вещам, порой пренебрежительного утилитарного отношения к тому, что мы именуем «неживой природой». Б. Латур предлагает пересмотреть философскую оптику в плане видения окружающего мира, научиться уважать вещи в их своеобразии. Он даже предложил образ «парламента вещей» [36, с. 166-180], которых долгое время лишали права голоса.

Таким образом, на данном примере, мы видим, что игра отражает постнеклассическое видение в различных регистрах, начиная от расхожих тем, связанных с опасениями относительно «восстания машин» и заканчивая текстуальностью нарративного пространства, бифуркационными механизмами развития сюжетной линии и вниманием к технике в ее представленности в качестве составной части повседневных практик.

\section{Заключение}

Таким образом, мы можем говорить о том, что видеоигры представляют собой феномен постнеклассической культуры, в котором проявляются ее основные императивы. Мы рассмотрели отражение лишь нескольких черт постнеклассики (эклектика и бриколаж, символизм, сотворчество, нелинейность) в видеоиграх, и данная работа может быть продолжена.

Как и другие феномены постнеклассической культуры, такие как, например, современное искусство, видеоигры неоднородны в плане наличия различных уровней смысловой наполненности: здесь может соседствовать ориентация на массового потребителя 
одновременно с наличием смысловых пластов для интеллектуально-ориентированного реципиента.

Видеоигры многослойны, интертекстуальны и семантически неоднородны, эклектично соединяют в себе различные культурные элементы, используя технику художественного бриколажа. Мы также показали, что видеоигры представляют собой новый медиум, который способен формировать неомифологическое пространство, выстраивая его на основе игры с архаической мифологической семантикой и символизмом, и вовлекая субъекта в творческий процесс.

Нарративная составляющая многих видеоигр предполагают нелинейную структуру, что также обнаруживает их принадлежность к постнеклассике. Наличие сложных нарративных конфигураций в играх часто связано с необходимостью решения моральных дилемм, суть которых соотнесена с моральным релятивизмом постнеклассики в целом. Интерактивность, нелинейность, иммерсивность видеоигр, наличие бифуркационных возможностей в рамках геймплея делают игру ярким феноменом постнеклассической культуры. Сложное нарративное устройство часто соседствует с символизмом в различных его проявлениях (действия игрока, персонажи, топосы пространства и хронотопы), что часто перекликается с психоаналитическими ходами мысли, ставшими неотьемлемой частью современного культурного пространства. Наконец, внимание к «вещности» мира, уставшей от семиозиса означающих, также присутствует в содержании современных видеоигр.

Исследование выполнено при финансовой поддержке гранта Президента Российской Федерации № $M K-1560.2018 .6$.

\section{СПИСОК ЛИТЕРАТУРЫ}

1. Степин В.С. Философская антропология и философия науки. - М.: Высшая школа, 1992. - 191 с.

2. Краснопольская А.П. Трансформация игровых стратегий в постнеклассической парадигме культуры // Вестник МГУКИ. - 2012. - № 1 (45). - С. 56-61.

3. Алиева Н.З. Постнеклассическое естественнонаучное образование: концептуальные и философские основания. - М.: Академия Естествознания, 2008. URL: https://monographies.ru/ru/book/view?id=7 (дата обращения 25.12.2019).

4. Можеко M.A. Классика-неклассика-постнеклассика // История философии. Энциклопедия. URL: http://www.velikanov.ru/philosophy/klassika neklassika postneklassika.asp (дата обращения 25.12.2019).

5. Иванова А.С. Классическая, неклассическая и постнеклассическая модели социального познания // Вестник Московского государственного областного университета. Серия «Философские науки». 2010. - № 3. - С. 22-29.

6. Гавриленко С.В. Постнеклассические ориентации в культуре: Методологический анализ: автореф. дис. ... канд. филос. наук. - Ростов-на-Дону, 2000. - 24 с.

7. Флиер А.Я. Модель культурной типологии: классическая, неклассическая и постнеклассическая культуры // Информационный гуманитарный портал «Знание. Понимание. Умение». - 2016. - № 1. - С. $11-$ 34.

8. Галанина Е.В., Батурин Д.А. Мифологические структуры в видеоиграх: архетипы // Вестник Томского государственного университа. Культурология и искусствоведение. - 2019. - № 36. - С. 31-48.

9. Галанина Е.В., Ветушинский А.С. Измерение героического и мономиф в видеоиграх // Вестник Томского государственного университета. Культурология и искусствоведение. - 2019. - № 33. - С. 34-46.

10. Видеоигры: введение в исследования / отв. ред. Е.В. Галанина. - Томск: Изд-во ТГУ, 2018. - 396 с.

11. Галанина Е.В., Батурин Д.А. Мифологический образ священного жертвоприношения в видеоиграх // Вестник Томского государственного университета. Культурология и искусствоведение. - 2018. № 31. - C. 21-34.

12. Салин А.С., Галанина Е.В. Миф о «расколдовывании мира» в видеоиграх в жанре horror // Векторы благополучия: экономика и социум. - 2018. - № 3 (30). - С. 73-82.

13. Галанина Е.В., Салин А.С. Мифическое в виртуальных мирах видеоигр // Философия и культура. 2017. - № 9. - C. 76-88. 
14. Галанина Е.В. Миф как реальность и реальность как миф: мифологические основания современной культуры. - М.: Академия Естествознания, 2013. - 129 с.

15. Строева О.В. Архетип героя в контексте неомифологизма современной экранной культуры // Вестник ВГИК. - 2019. - Т. 11. - № 2 (40). - С. 116-126.

16. Леви-Строс К. Неприрученная мысль // Первобытное мышление. - М.: Республика, 1994. - С. $126-130$.

17. Леви-Строс К. Мифологики: Сырое и приготовленное. - М.: Флюид, 2006. - 339 с.

18. Батракова С.П. Искусство и миф: Из истории живописи ХХ века. - М.: Наука, 2002. - 215 с.

19. Тихонова С.В. Мифологические основания социального феномена компьютерной игры // Социальная политика и социология. - 2009. - № 1. - С.199-212.

20. Рикер П. Герменевтика и психоанализ. Религия и вера. - М.: Искусство, 1996. - 270 с.

21. Делез Ж., Гваттари Ф. Анти-Эдип: Капитализм и шизофрения. - Екатеринбург: У-Фактория. 2007. $672 \mathrm{c}$.

22. Пригожин И., Стенгерс И. Порядок из хаоса: Новый диалог человека с природой. - М.: Прогресс, 1986. $-432 \mathrm{c}$.

23. Оводова С.Н. Текст в постнеклассической культуре // Вестник Полоцкого государственного университета. Серия Е «Педагогические науки». - 2014. - № 7. - С. 109-113.

24. Тищенко П.Д. Кризис научной рациональности как культурный фон возникновения и развития антипсихиатрии // Вестник НПА. Независимый психиатрический журнал. - 2011. - C. 10-13. URL: http://www.npar.ru/journal/2011/2/02-tischenko-2.htm (дата обращения 25.12.2019).

25. Рендл М.В. Модель «Открытого произведения» в социокультурном пространстве постнеклассической научной парадигмы // Вестник СамГУ. - 2015. - № 1 (123). - С. 28-33.

26. Эко У. Открытое произведение. Форма и неопределенность в современной поэтике. - СПб.: Академический проект, 2004. - 384 с.

27. Aarseth E.J. Cybertext: perspectives on ergodic literature. - Baltimore, London: The Johns Hopkins University Press, 1997. - 216 p.

28. Эко У. Имя розы. - Воронеж: Фолиант, 1993. - 536 с.

29. Эко У. Заметки на полях «Имени розы». - СПб.: Симпозиум, 2007. - 92 с.

30. Cremin C. Exploring videogames with Deleuze and Guattari: towards an affective theory of form. - NY: Routledge, 2016. - 158 p.

31. McLuhan M. Myth and Mass Media // Daedalus. - 1959. - V. 88 (2). - P. 339-348.

32. Философский словарь / авт.-сост. С.Я. Подопригора, А.С. Подопригора. - Ростов н/Д: Феникс, 2013. $562 \mathrm{c}$.

33. Рендл М.В. Актуализация метафизического хаоса в современной философии // Вестник ВУиТ. - 2014. - № 3 (16). - С. 127-136.

34. Делез Ж. Гваттари Ф. Тысяча плато: Капитализм и шизофрения. - Екатеринбург: У-Фактория; М.: Астрель, 2010. - 895 с.

35. Ламеко Н.В. «Хаосмос» Джеймса Джойса как мультистабильная система (синергетическая природа художественного феномена) // Веснік БдУ. Серыя 4, Філалогія. Журналістыка. Педагогіка. - 2005. № 3. - C. 37-41.

36. Latour B. Politics of nature. How to bring the sciences into democracy. - Cambridge: Harvard University Press, 2004. -320 p.

Поступила 03.01.2020 г. 
UDC 316.75:794:004.946

\title{
VIDEO GAMES IN THE CONTEXT OF POST-NON-CLASSICAL CULTURE
}

\author{
Ekaterina V. Galanina1,2, \\ galanina@tpu.ru \\ Yury M. Shaev3, \\ existentia20065@yandex.ru \\ ${ }^{1}$ National research Tomsk Polytechnic University, \\ 30, Lenin avenue, Tomsk, 634050, Russia. \\ 2 Tomsk State University, \\ 36, Lenin avenue, Tomsk, 634050, Russia. \\ 3 Pyatigorsk State University, \\ 9, Kalinin avenue, Pyatigorsk, 357532, Russia.
}

Ekaterina V. Galanina, Cand. Sc., associate professor, National research Tomsk Polytechnic University; associate professor, Tomsk State University.

Yury M. Shaev, Cand. Sc., associate professor, Pyatigorsk State University.

This article is devoted to the study of video games in the context of post-non-classical culture. On the one hand, video games are a product of modern culture which is at the post-non-classical stage of its development associated with a new type of rationality and the philosophical discourse of postmodernism. On the other hand, video games as new media, possessing mythological power and involving the subject in their space, activate archaic semantic strata. Video games have a significant impact on the mass consciousness, forming ideological and value-semantic attitudes. They can be investigated as a product of myth-making and myth-design. The aim of the article is to explore video games as a neo-mythological phenomenon in the context of post-nonclassical culture. Methods: general philosophical research methods, comparative historical method, hermeneutic analysis, methods of applied ludology. Results. We have highlighted and described the main features of post-non-classical culture. Video games are investigated as a product of post-non-classical culture, reflecting its main features and experience of the world vision of a modern individual. We have come to the conclusion that post-non-classical culture, legitimizing various types of rationality and discourse, leading to the image of an unstable, chaotic and disproportional world, actualizing archaic representations displaced before classical culture, is close to myth in its world vision. Video games as a non-mythological phenomenon show us the following features of post-non-classics: eclecticism, bricolage, symbolism, co-creation and non-linearity.

Key words: Video game, post-non-classical culture, game, post-modernism, myth, bricolage, eclecticism, symbolism, narrative, non-linearity, co-creation.

The research was financially supported by the grant of the President of the Russian Federation no. $M K-1560.2018 .6$.

\section{REFERENCES}

1. Stepin V.S. Filosofskaya antropologiya i filosofiya nauki [Philosophical anthropology and philosophy of science]. Moscow, Vysshaya shkola Publ., 1992. 191 p.

2. Krasnopolskaya A.P. Transformatsiya igrovykh strategiy v postneklassicheskoy paradigme kultury [Games strategies transformation in post-nonclassical cultural paradigm]. Vestnik MGUKI, 2012, no. 1 (45), pp. 56-61. 
3. Alieva N.Z. Postneklassicheskoe estestvennonauchnoe obrazovanie: kontseptualnye i filosofskie osnovaniya [Post-nonclassical science education: conceptual and philosophical foundations]. Moscow, Akademiya Estestvoznaniya Publ., 2008. Available at: https://monographies.ru/ru/book/view?id=7 (accessed 25 December 2019).

4. Mozheko M.A. Klassika-neklassika-postneklassika [Classics-Neclassics-Postclassics]. Available at: http://www.velikanov.ru/philosophy/klassika_neklassika_postneklassika.asp (accessed 25 December 2019).

5. Ivanova A.S. Klassicheskaya, neklassicheskaya i postneklassicheskaya modeli sotsialnogo poznaniya [Classical, non-classical and post-non-classical models of social cognition]. Vestnik Moskovskogo gosudarstvennogo oblastnogo universiteta. Seriya «Filosofskie nauki», 2010, no. 3, pp. 22-29.

6. Gavrilenko S.V. Postneklassicheskie orientatsii v kulture: metodologicheskiy analiz. Avtoref. Diss. Kand. nauk [Post-non-classical orientations in culture: Methodological analysis. Cand. Diss. Abstract]. Rostov-onDon, 2000. 24 p.

7. Flier A.Ya. Model kulturnoy tipologii: klassicheskaya, neklassicheskaya i postneklassicheskaya kultury [Model of cultural typology: classical, non-classical and post-non-classical cultures]. Informatsionny gumanitarny portal «Znanie. Ponimanie. Umenie», 2016, no. 1, pp. 11-34.

8. Galanina E.V., Baturin D.A. Mifologicheskie struktury v videoigrakh: arkhetipy [Mythological structures in video games: archetypes]. Vestnik Tomskogo gosudarstvennogo universiteta. Kulturologiya $i$ iskusstvovedenie, 2019, no. 36, pp. 31-48.

9. Galanina E.V., Vetushinskiy A.S. Izmerenie geroicheskogo i monomif v videoigrakh [Dimension of the heroic and monomith in video games]. Vestnik Tomskogo gosudarstvennogo universiteta. Kulturologiya $i$ iskusstvovedenie, 2019, no. 33, pp. 34-46.

10. Videoigry: vvedenie v issledovaniya [Video games: an introduction to research]. Ed. by E.V. Galanina. Tomsk, TGU Publ., 2018. 396 p.

11. Galanina E.V., Baturin D.A. Mifologicheskiy obraz svyashchennogo zhertvoprinosheniya v videoigrakh [The mythological image of sacrification in video games]. Vestnik Tomskogo gosudarstvennogo universiteta. Kulturologiya i iskusstvovedenie, 2018, no. 31, pp. 21-34.

12. Salin A.S., Galanina E.V. Mif o «raskoldovyvanii mira» v videoigrakh v zhanre horror [The «world disenchantment» myth in horror video games]. Vektory blagopoluchiya: ekonomika i sotsium, 2018, no. 3 (30), pp. 73-82.

13. Galanina E.V., Salin A.S. Mificheskoe v virtualnykh mirakh videoigr [Mythical in the virtual worlds of video games]. Filosofiya i kultura, 2017, no. 9, pp.76-88.

14. Galanina E.V. Mif kak realnost i realnost kak mif: mifologicheskie osnovaniya sovremennoy kultury [Myth as reality and reality as myth: mythological foundations of modern culture]. Moscow, Akademiya Estestvoznaniya Publ., 2013. 129 p.

15. Stroeva O.V. Arkhetip geroya v kontekste neomifologizma sovremennoy ekrannoy kultury [Archetype of the hero in the context of neomythologism of modern screen culture]. Vestnik VGIK, 2019, vol. 11, no. 2 (40), pp. $116-126$.

16. Levi-Stross C. Nepriruchennaya mysl [Untamed thought]. Pervobytnoe myshlenie [Primitive thinking]. Moscow, Respublika Publ., 1994. pp. 126-130.

17. Levi-Stross C. Mifologiki: syroe i prigotovlennoe [Mythologists: raw and cooked]. Moscow, Flyuid Publ., 2006. 339 p.

18. Batrakova S.P. Iskusstvo $i$ mif: iz istorii zhivopisi $X X$ veka [Art and myth: from the history of $20^{\text {th }}$ century painting]. Moscow, Nauka Publ., 2002. 215 p.

19. Tikhonova S.V. Mifologicheskie osnovaniya sotsialnogo fenomena kompyuternoy igry [The mythological foundations of the social phenomenon of a computer game]. Sotsialnaya politika i sotsiologiya, 2009, no. 1, pp. 199-212.

20. Riker P. Germenevtika i psikhoanaliz. Religiya i vera [Hermeneutics and psychoanalysis. Religion and Faith]. Moscow, Iskusstvo Publ., 1996. 270 p.

21. Delez Dzh., Gvattari F. Anti-edip: kapitalizm i shizofreniya [Anti-oedipus: capitalism and schizophrenia]. Ekaterinburg, U-Faktoriya Publ., 2007. 672 p.

22. Prigozhin I., Stengers I. Poryadok iz khaosa: novy dialog cheloveka s prirodoy [Order out of chaos: a new dialogue between man and nature]. Moscow, Progress Publ., 1986. 432 p.

23. Ovodova S.N. Tekst v postneklassicheskoy kulture [Text in post-non-classical culture]. Vestnik Polotskogo gosudarstvennogo universiteta. Seriya E «Pedagogicheskie nauki», 2014, no. 7, pp. 109-113.

24. Tishchenko P.D. Krizis nauchnoy ratsionalnosti kak kulturny fon vozniknoveniya i razvitiya antipsikhiatrii [The crisis of scientific rationality as a cultural background for the emergence and development of antipsychiatry]. Vestnik NPA. Nezavisimy psikhiatricheskiy zhurnal, 2011, pp. 10-13. Available at: http://www.npar.ru/journal/2011/2/02-tischenko-2.htm (accessed 25 December 2019). 
25. Rendl M.V. Model «Otkrytogo proizvedeniya» v sotsiokulturnom prostranstve postneklassicheskoy nauchnoy paradigmy [The model of the «Open Work» in the sociocultural space of the post-non-classical scientific paradigm]. Vestnik SamGU, 2015, no. 1 (123), pp. 28-33.

26. Eko U. Otkrytoe proizvedenie. Forma i neopredelennost v sovremennoy poetike [Open work. Form and uncertainty in contemporary poetics]. St. Petersburg, Akademicheskiy proekt Publ., 2004. 384 p.

27. Aarseth E.J. Cybertext: perspectives on ergodic literature. Baltimore, London, The Johns Hopkins University Press, 1997. 216 p.

28. Eko U. Imya rozy [Rose name]. Voronezh, Foliant Publ., 1993. 536 p.

29. Eko U. Zametki na polyakh «Imeni rozy» [Notes on «Rose name»]. St. Petersburg, Simpozium Publ., 2007. $92 \mathrm{p}$.

30. Cremin C. Exploring videogames with Deleuze and Guattari: towards an affective theory of form. NY, Routledge, 2016. 158 p.

31. McLuhan M. Myth and Mass Media. Daedalus. 1959, vol. 88 (2), pp. 339-348.

32. Filosofskiy slovar [Philosophical dictionary]. Compliers S.Ya. Podoprigora, A.S. Podoprigora. Rostov-onDon, Feniks Publ., 2013. 562 p.

33. Rendl M.V. Aktualizatsiya metafizicheskogo khaosa v sovremennoy filosofii [Actualization of metaphysical chaos in modern philosophy]. Vestnik VUiT, 2014, no. 3 (16), pp. 127-136.

34. Delez Dzh., Gvattari F. Tysyacha plato: Kapitalizm $i$ shizofreniya [The thousand plateaus: capitalism and schizophrenia]. Ekaterinburg, U-Faktoriya Publ.; Moscow, Astrel Publ., 2010. 895 p.

35. Lameko N.V. «Khaosmos» Dzheymsa Dzhoysa kak multistabilnaya sistema (sinergeticheskaya priroda khudozhestvennogo fenomena) [James Joyce's Chaosmos as a multistable system (synergetic nature of the artistic phenomenon)]. Vesnik BDU. Seryya 4 «Filalogiya. Zurnalistyka. Pedagogika», 2005, no. 3, pp. 37-41.

36. Latour B. Politics of nature. How to bring the sciences into democracy. Cambridge, Harvard University Press, 2004. 320 p.

Received: 3 January 2020. 